\title{
Pengaruh Pijat Bayi oleh Ibu Terhadap Perubahan Berat Badan pada Ibu Postpartum
}

\author{
Anis Nikmatul Nikmah ${ }^{1}$, Galuh Pradian Yanuariningsih ${ }^{1}$ \\ Fakultas Ilmu Kesehatan Universitas Kadiri, Indonesia ${ }^{1}$ \\ e-mail:anisnikmatul@unik-kediri.ac.id
}

\begin{abstract}
Mother 's massage is the kind of comunication between mother and baby by touching. Chest massage and stomach masssage will stimulate the parasympathetic nerve and the stomach to produce gastrin hormone and increase the motility of stomach and abdomen, so it will make easin the mix, push and absorb the nutrient of food well. The purpose of the study is to know the inf luence of baby massage of mother toward the post partum mother's weight change. The research method was quasi experimental with two Group pre-test and post-test design. The population are postpartum mother and baby in 2 weeks - 1 month without any diferences of sample taking. The sample were 32 respondents which consists of 2 intervension group both of group were done pretest of baby weight then giving intervension during two weeks, after that doingpost test by measuring baby weight. The resulth of the study used paired sample t-test with Wilcoxon test. It got pvalue 0.007 of theathment group and 0.000 of control group with dispule between treatment and control group p-value 0.000. Based on the analysis, there is the influence of baby's massage of mother toword the weight change for postpartum mother in 2019. This research can be used as an alternative to apply during postpartum mother's care and breasfeeding mother with involve the mother's role during the baby's daily care for the baby and mother's happiness.
\end{abstract}

Keywords: baby massage, body weigh, post patum

\section{Pendahuluan}

Pertumbuhan bayi merupakan perubahan yang terbatas pada pola fisik yang dialami oleh bayi (Sembiring, 2019). Pertumbuhan bersifat kuantitatif sehingga dapat diukur dengan satuan berat. Peningkatan berat badan pada bayi merupakan indikator yang sangat sensitif untuk memantau pertumbuhan dan kesehatan bayi (Novianti D, 2014). Pola pertumbuhan dan perkembangan setiap bayi berbeda, untuk mencapai pertumbuhan dan perkembangan yang optimal dibutuhkan stimulasi (Gilasi et al, 2017).

Stimulasi adalah merupakan hal yang harus dilakukan agar kecerdasan bayi secara optimal. Semakin banyak stimulasi diberikan semakin banyak cabang neuron yang terbentuk, sehingga terbentuk komunikasi sel antar otak yang baik (Hall, 2012). Stimulasi yang bisa diberikan diantaranya adalah sentuhan fisik (Novianti, D, 2014). Pijat bayi adalah salah satu terapi sentuhan pada bayi (Ct, 2019). Setelah lahir, pengalaman sentuhan bayi baru lahir biasanya diberikan oleh ibu selama pemberian perawatan primer. Ibu biasanya memberikan stimulasi taktil melalui kontak kulit dan melalui sentuhan yang mencakup membelai lembut dan pijat
(Clark et al, 2015). Pijat bayi dianggap sebagai metode perawatan baru untuk neonatus yang meberikan efek postif pada masa neonatal dan perawatan kesehatan. Banyak manfaat yang didapatkan dari pijat bayi diantaranya meningkatkan perkembangan fisik dan intelektual, kekebalan, pencernaan dan komunikasi emosional antara ibu dan bayi (Lei et al., 2018).

Unsur utama pijat bayi adalah sentuhan (touch) bukan tekanan (pressure). Oleh sebab itu selain oleh terapis spesialis, pijat bayi sangat baik di lakukan oleh ibu atau ayah (Fallah et al., 2013). Berdasarkan penelitian sebelunya bahwa pijat bayi yang dilakukan secara berulang mampu menurunkan kadar plasma gastrin, insulin dan somatotosin, meningkatakan kadar plasma glukosa dan kenaikan berat badan( $\mathrm{T}$ et al., 2005).

Berdasarkan hasil wawancara kepada ibu mengatakan bayinya dipijat saat bayi panas karena kecapekan, sering rewel, dan tidak enak badan. Dan ibu takut saaat melkukan pemijatan beralasan tulang bayi yang masih lunak. Ibu langsung membawa bayi ke tempat urut tradisional yang dikenalinya. 
Hal ini sejalan dengan penelitian pijat bayi yang dilakukan oleh ibu bayi sendiri menunjukan peningkatan berat badan yang lebih signifikan dibandingakan dengan pijat yang dilakukan oleh petugas kesehatan yang bisa melakukan pijat bayi, sehingga dampak lain yang didapat adalah memungkinkan penerapan pengobatan dengan biaya efektif dalam perawatan intensif neonatal (Articles, $T, 2002$ ). Tujuan penelitian ini adalah untuk mengetahui pengaruh pijat bayi oleh ibu terhadap perubahan berat badan pada ibu post partum di Kabupaten Tulungagung Tahun 2019.

\section{Metode Penelitian}

Metode yang digunakan dalam penelitian ini adalah penelitian eksperimen semu atau quasy experiment dengan rancangan non randomized pretest and posttest with control group design yang digunakan untuk mengetahui pengaruh pijata bayi oleh ibu terhadap perubahan berat bada pada ibu post partum.

\subsection{Metode Pengumpulan Data}

Berdasarkan tempat penelitian termasuk penelitian lapangan yang dilakukan di wilayah kerja puskesmas Tulungaung Pada bulan Mei-Juni 2019. Berdasarkan cara pengumpulan data melalui observasi yang dilakukan dengan pemeriksaan secara langsung dan lembar kuesioner.

Populasinya adalah semua ibu post partum yang memiliki bayi lahir normal, sampel yang digunakan adalah ibu postpatum dan bayi usia $>$ dari 2 minggu dengan keadaan ibu dan bayi sehat. Sampel dipilih secara incidental sampling dengan besar sampel 32 responden. Sebelum dilakukan intervensi bayi dilakukan pengukuran berat badan, diberikan pemijatan selama 2 minggu kemudian dilakukan penimbangan ulang.

\subsection{Metode Analisis Data}

Analisis univariat digunakan untuk mengidentifikasi gambaran umum dari responden. Analisis bivariat yang digunakan untuk mengungkap pengaruh pijat bayi oleh ibu terhadap perubahan berat badan, data yang digunakan adalah rasio.

Uji normalitas data menggunakan shapiro-wilk apabila data normal mengungkap perbedaan kelompok berpasangan dengan distribusi data normal menggunakan uji t-test (paired t-test), untuk mengetahui perbedaan kelompok tidak berpasangan dengan distribusi data normal menggunakan independent t-test, apabila distribusi data tidak normal menggunakan uji wilcoxon dan mann whitney.

\section{Hasil dan Pembahasan}

Analisis univariat pada Tabel 1 menggambarkan identifikasi karakteristik responden. analiais bivariat menggunakan uji wilcoxon karena distribusi data tidak normal. Untuk uji selisih perubahan berat badan kelompok perlakuan dan kontrol dengan menggunakan uji beda kelompok tidak berpasangan yaitu uji paired t-test.

Tabel 1. Distribusi frekuensi karakteristik responden berdasarkan umur

\begin{tabular}{cccc}
\hline \multirow{2}{*}{$\begin{array}{c}\text { Kriteria } \\
\text { umur }\end{array}$} & \multicolumn{2}{c}{ Kelompok } & Tontrol \\
\cline { 2 - 3 } & $(\%)$ & $\begin{array}{c}\text { Perlakuan } \\
(\%)\end{array}$ & $\begin{array}{c}\text { Total } \\
(\%)\end{array}$ \\
\hline \multirow{2}{*}{ 20 tahun } & 0 & 1 & 1 \\
& $0 \%$ & $6,3 \%$ & $3,1 \%$ \\
$20-35$ tahun & 15 & 14 & 29 \\
& $93,8 \%$ & $87,5 \%$ & $90,6 \%$ \\
$>35$ tahun & 1 & 1 & 2 \\
& $6,3 \%$ & $6,3 \%$ & $6,3 \%$ \\
\hline Total & 16 & 16 & 32 \\
\hline
\end{tabular}

Berdasarkan tabel 1. Karakteristik responden berdasarkan umur menunjukkan hampir seluruhnya pada kelompok kontrol usia 20-35 tahun, pada kelompok perlakuan hampir seluruhnya usia 20-35 tahun.

Berdasarkan Tabel 2. Karakteristik responden menurut pekerjaan menunjukkan sebagaian besar responden pada kelompok kontrol tidak bekerja, pada kelompok perlakuan hampir seluruhnya responden tidak bekerja.

Tabel 2: Distribusi frekuensi karakteristik responden berdasarkan pekerjaan

\begin{tabular}{|c|c|c|c|}
\hline \multirow[b]{2}{*}{$\begin{array}{c}\text { Kriteria } \\
\text { pekerjaan }\end{array}$} & \multicolumn{2}{|c|}{ kelompok } & \multirow[b]{2}{*}{$\begin{array}{c}\text { Total } \\
(\%)\end{array}$} \\
\hline & $\begin{array}{c}\text { Kontrol } \\
(\%)\end{array}$ & $\begin{array}{c}\text { Perlakuan } \\
\text { (\%) }\end{array}$ & \\
\hline Bekerja & $\begin{array}{c}5 \\
313 \%\end{array}$ & $\begin{array}{c}2 \\
12.5 \%\end{array}$ & $\begin{array}{c}7 \\
219 \%\end{array}$ \\
\hline $\begin{array}{c}\text { Tidak } \\
\text { bekerja }\end{array}$ & $\begin{array}{c}11 \\
68,7 \% \\
\end{array}$ & $\begin{array}{c}14 \\
87,5 \% \\
\end{array}$ & $\begin{array}{c}25 \\
78,1 \% \\
\end{array}$ \\
\hline Total & 16 & 16 & 32 \\
\hline
\end{tabular}


bahwa terdapat data yang tidak berdistribusi normal.

Tabel 3. Uji normalitas karakteristik perubahan berat badan pada kelompok perlakuan dan kontrol

\begin{tabular}{lccc}
\hline \multirow{2}{*}{ Kelompok } & \multicolumn{2}{c}{ Shapiro-wilk } & \multirow{2}{*}{ Sig. } \\
\cline { 2 - 3 } & statistic & $\mathrm{df}$ & \\
Pre kontrol BB &, 936 & 16 &, 302 \\
Post kontrol BB &, 845 & 16 &, 011 \\
$\begin{array}{l}\text { Pre perlakuan } \\
\text { BB }\end{array}$ &, 304 & 16 &, 000 \\
Post perlakuan &, 976 & 16 &, 926 \\
BB &, 764 & 16 &, 001 \\
Selisih BB & & & \\
\hline
\end{tabular}

Perbedaan rata-rata berat badan bayi pada kelompok perlakuan ditampilkan pada Tabel 4.

Tabel 4 Perbedaan rata- rata berat badan bayi pada kelompok perlakuan

\begin{tabular}{|c|c|c|c|c|}
\hline Variabel & Jumlah & Median & Min-Maks & $\begin{array}{c}\mathrm{p}- \\
\text { value }\end{array}$ \\
\hline Pretest & 16 & 3550 & $2800-3900$ &, 007 \\
\hline Post test & 16 & 3950 & $3200-4600$ & \\
\hline
\end{tabular}

rata perbandingan berat badan pretestposttest pada kelompok perlakuan didapatkan meningkat 400 gram. Hasil uji statistik didapatkan nilai $\mathrm{p}$ value $=0,007$. terdapat perbedaan signifikan rata- rata perbandingan berat badan pada kelompok perlakuan.

Perbedaan rata-rata berat badan bayi pada kelompok kontrol disajikan pada Tabel 5.

Tabel 5 Perbedaan rata- rata berat badan bayi pada kelompok kontrol

\begin{tabular}{ccccc}
\hline Variabel & Jumlah & Median & Min-Maks & $\begin{array}{c}\text { p- } \\
\text { value }\end{array}$ \\
\hline Pretest & 16 & 3150 & $2800-3800$ &, 000 \\
\hline Post test & 16 & 3400 & $3000-4300$ & \\
\hline
\end{tabular}

Tabel 5 menunjukkan bahwa rata-rata perbandingan berat badan pretest-posttest pada kelompok kontrol didapatkan meningkat 250 gram. Hasil uji statistik didapatkan nilai $\mathrm{p}$ value $=0,000$. terdapat perbedaan signifikan rata- rata perbandingan berat badan pada kelompok kontrol. Tabel 6 menunjukkan perbandingan rata-rata berat badan bayi kelompok perlakuan dan kotrol. Tabel 6. Distribusi perbandingan rata- rata berat badan bayi pada kelompok perlakuan dan kelompok kontrol

\begin{tabular}{ccccc}
\hline Variabel & Jumlah & Median & Min-Maks & $\begin{array}{c}\text { p- } \\
\text { value }\end{array}$ \\
\cline { 1 - 4 } Perlakuan & 16 & 3950 & $3200-4600$ & \\
\cline { 1 - 3 } Kontrol & 16 & 3400 & $3000-4300$ & ,003 \\
\cline { 1 - 2 } Hasil uji analisis uji & beda kelompok \\
tidak berpasangan & dengan & menggunakan
\end{tabular}

Mann-Whiney didapatkan nilai p-value 0,003 . Terdapat perbedaan rerata kelompok perlakuan dengan kelompok kontrol.

Berdasarkan data yang diperoleh menunjukkan distribusi usia responden hampir seluruhnya usia 20-35 tahun pada kelompok perlakuan maupun kelompok kontrol. responden dengan usia muda menunjukkan ketergantungan pada keluarga dan ketidaktahuan apa yang harus dilakukan. Usia responden pada penelitian ini menunjukkan kesiapan dalam melakukan pijat bayi tanpa bantuan orang lain.

Berdasarkan pekerjaan sebagian besar resonden tidak bekerja. Bayi yang berada dalam dekapan ibu karena menyusu akan merasakan kasih sayng ibunya. Bayi akan merasa aman, terutama saat mendengarkan detak jantung ibunya yang dikenal sejak masa prenatal (Roesli, 2001). Responden yang tidak bekerja akan lebih banyak meluangkan waktu untuk melakukan pijat bayi kepada anaknya.

Sebelum dilakukan perlakuan pijat bayi, dilakukan pengukuran berat badan pada kedua kelompok. Didapatkan perbedaan rerata kenaikan berat badan 400 gram pada kelompok perlakuan dan 250 gram pada kelompok kontrol. uji analisis perbedaan rerata kelompok perlakuan dengan kelompok kontril didapatkan nilai $\mathrm{p}$ value 0,003 , sehingga ada pengaruh pijat bayi oleh ibu terhadap perubahan berat badan bayi.

Pijatan merupakan sentuhan sistematis yang dilakukan dengan teknik sentuhan (Roesli U, 2001). Pemijatan yana dilakukan pada bayi akan merangsang nervus vagus; saraf ini akan meningkatkan kerja peristaltik usus sehingga terjadi pengosongan lambung meningkat kemudian akan merangsang nafsu makan bayi untuk makan lebih lahap dalam jumlah yang cukup. Selain itu nervus vagus dapat memacu produksi enzim pencernaan sehingga penyerapan makanan bisa maksimal.

Pijat bayi merupakan tradisi lama yang digali kembali dengan sentuhan ilmu kesehatan dan tinjauan ilmiah yang bersumber dari penelitian -penelitian para ahli neonatology, saraf dan psikologi anak. Di cina, pijat menjadi bagian yang tidak terpisahkan dari kehidupan manusia. Pijat 
merupakan terapi luar yang sangat mujarab dan diandalkan dalam pengobatan berbagai penyakit (Sembiring, 2019).

Penelitian sebelunya bahwa pijat bayi yang dilakukan secara berulang mampu menurunkan kadar plasma gastrin, insulin dan somatotosin, meningkatakan kadar plasma glukosa dan kenaikan berat badan ( $\mathrm{T}$, S. H. et al., 2005). Perkembangan sensori bayi sudah dimulai sejak awal kehidupan diadalam uterus (Clark et al, 2015).

Penelitian lain menyatakan adanya manfaat yang baik terhadap bayi prematur yang diberikan pijatan oleh ibunya sendiri (Abdallah, Kursahi and Hawwari, 2013). Pijat bayi diharapkan dapat dilakukan oleh ibu, karena manfaat yang didapatkan dari pijat tersebut yang terpenting akan lebih meningkatkan kedekatan antara ibu dan bayinya.

Bayi baru lahir memerlukan stimulus untuk pertumbuhan dan perkembangan. Stimulus tersebut diantaranya adalah pijat bayi. Pijat bayi merupakan intervensi yang sangat bermanfaat bagi bayi (Abdallah, Kurdahi and Hawwari, 2013). Pemijatan yang dilakukan pada bayi akan merangsang nervus vagus, saraf ini akan meningkatkan kerja peristaltik usus sehingga terjadi pengosongan lambung meningkat kemudian akan merangsang nafsu makan bayi untuk makan lebih lahap dalam jumlah yang cukup.

Selain itu nervus vagus dapat memacu produksi enzim pencernaan sehingga penyerapan makanan bisa maksimal (Ti, Diego et al, 2007). Disisi lain pijat juga dapat memperlancar peredaran darah dan meningkatkan metabolisme sel, dari rangkaian tersebut berat badan bayi akan meningkat (Kassolik et al., 2015). Sehingga dengan adanya peningkatan motilitas lambung dan usus akan mempermudah pencampuran, pendorongan makanan dan penyerapan nutrisi menjadi lebih baik (Hall. J, 2012)

Manfaat yang didapat dari pijat bayi adalah mencegah prematuritas, meningkatkan pertumbuhan, meningkatkan perhatian, mengurangi masalah motorik, meningkatkan fungsi kekebalan tubuh (Ti, Diego et al, 2007).

\section{Simpulan dan Saran 4.1 Simpulan}

Ada pengaruh pijatan bayi pada ibu terhadap perubahan berat badan ibu nifas pada tahun 2019.

\subsection{Saran}

Hasil penelitian ini dapat digunakan sebagai alternatif untuk diterapkan selama perawatan ibu nifas dan menyusui dengan melibatkan peran ibu sehari-hari selama merawat bayi

\section{Daftar Pustaka}

Abdallah, B., Kurdahi, L. and Hawwari, M. (2013) 'Infant Behavior and Development The efficacy of massage on short and long term outcomes in preterm infants', Infant Behavior and Development. Elsevier Inc., 36(4), pp. 662-669. doi: 10.1016/j.infbeh.2013.06.009.

Articles, T. (2002) 'Infant Massage as a Component of Developmental Care : Past, Present, and Future', 17(1), pp. 1-7.

Clark-gambelunghe, M. B. and Clark, D. A. (2015) 'Sensory Development Neonate Sensory Vision Hearing Oral development Taste Smell', Pediatric Clinics of NA. Elsevier Inc. doi: 10.1016/j.pcl.2014.11.003.

Ct, A. B. S. T. R. A. (2019) 'Social touch, CT touch and massage therapy: A narrative review', 51(December 2018), pp. 123-145. doi: 10.1016/j.dr.2019.01.002.

Fallah, R. et al. (2013) 'Early Human Development Sun fl ower oil versus no oil moderate pressure massage leads to greater increases in weight in preterm neonates who are low birth weight th', Early Human Development. Elsevier B.V., 89(9), pp. 769-772. doi: 10.1016/j.earlhumdev.2013.06.002.

Gilasi, H. R., Atrian, M. K. and Hosseinian, M. (2017) 'The effect of tactilekinesthetic stimulation on growth indices of healthy neonates', Journal 
of Bodywork \& Movement Therapies.

Elsevier Ltd. doi:

10.1016/j.jbmt.2017.08.005.

Hall, J. (2012) Buku ajar fisiologi kedokteran. Edited by antonia tanzil m. widjaja kusumuh. elisivier (singapore) ple ld.

Kassolik, K. et al. (2015) 'The effectiveness of massage based on the tensegrity principle compared with classical abdominal massage performed on patients with constipation', Archives of Gerontology and Geriatrics. Elsevier Ireland Ltd. doi: 10.1016/j.archger.2015.05.011.

Lei, M. et al. (2018) 'International Journal of Nursing Sciences Effects of massage on newborn infants with jaundice: A meta-analysis', International Journal of Nursing Sciences. Elsevier Taiwan LLC, 5(1), pp. 89-97. doi: 10.1016/j.jinss.2018.01.004.

Novianti, D. (2014) Anak- Anak Kita Pengukir Peradapan.

Roesli, O. (2001) Pedoman Pijat Bayi Premature.

Sembiring, J. B. R. (2019) Asuhan Neonatus Bayi, Balita, Anak Pra Sekolah. pertama.

T, S. H. et al. (2005) 'Massage-like stroking influences plasma levels of gastrointestinal hormones, including insulin, and increases weight gain in male rats', 120, pp. 73-79. doi: 10.1016/j.autneu.2005.04.007.

Ti, V., Diego, M. and Hernandez-reif, M. (2007) 'Massage therapy research', 27, pp. 75-89. doi: 10.1016/j.dr.2005.12.002. 